\title{
Sustainable Procedure for Using Waste of Date Seeds as a Reinforcement Material for Polymeric Composites
}

\author{
Ali I. Al-Mosawi', Shaymaa Abbas Abdulsada', Abbass A. Hashim² \\ ${ }^{1}$ Faculty of Materials Science and Engineering, University of Miskolc, Miskolc, Hungary \\ ${ }^{2}$ University of Wolverhampton, Wolverhampton, UK \\ Email: qkoali76@uni-miskolc.hu, qkosha86@uni-miskolc.hu, a.hashim@shu.ac.uk
}

How to cite this paper: Al-Mosawi, A.I., Abdulsada, S.A. and Hashim, A.A. (2018) Sustainable Procedure for Using Waste of Date Seeds as a Reinforcement Material for Polymeric Composites. Open Access Library Journal, 5: e4384.

https://doi.org/10.4236/oalib.1104384

Received: January 28, 2018

Accepted: March 9, 2018

Published: March 12, 2018

Copyright ( 2018 by authors and Open Access Library Inc.

This work is licensed under the Creative Commons Attribution International License (CC BY 4.0).

http://creativecommons.org/licenses/by/4.0/

\section{(c) (i) Open Access}

\begin{abstract}
In this article, particles of date seeds as a natural strengthening of the polyester resin and reinforcing percentages $(1,2,3)$ wt $\%$ were used. For the purpose of comparison with the properties that were obtained in these composite materials reinforced by date seeds, particles have been manufacturing a composite material of the same resin reinforced particles calcium carbonate industrial, the same reinforcing percentages above. Results showed the samples that contain date seeds have a high resistance strain compared to models that contain calcium carbonate and this increase in tensile strength increases with the amount of particles date seeds, plus a big improvement in impact resistance samples have particles date seeds and increases with increasing reinforcement ratio compared with sample have calcium carbonate particles.
\end{abstract}

\section{Subject Areas}

Environmental Sciences

\section{Keywords}

Date Seeds, Recycling Waste, Sustainable Composite Material

\section{Introduction}

The accumulation of agricultural industries wastes considered as significant environmental problems in many countries around the world and with plants, where there are no waste recycling plants, or they do not have the competence required to complete the process of recycling. One of these types of plant waste is the date seeds. Date seeds are considered as a dry waste, which has lightweight, 
large size (i.e. low density and quality), and these wastes accumulated in large quantities causing a real problem because it is considered one of the environmental pollutants when burned, in addition to being a shelter for rodents and insects. Therefore, it is important to find out how to incorporate these wastes in the applications of green and sustainable engineering as a competitor environmental and economical alternative for synthesis materials existing and to be used only in the feed industry. One of the areas using the waste of date seeds is in the manufacturing of engineering parts based on composite materials.

The use of these applications for sustainable or green works to achieve sustainable development, which is the real development, has the ability to communicate and stability from the perspective of their use of natural resources and take the environmental balance as the essential base [1]-[7]. The Babylonians, who use the manufacturing technology of composite materials and the concept of sustainable development as the Babylonians build their homes by agricultural waste (like the hay) with mud to strengthen it. Thus, Iraq was the first country in the world that applied the principle of sustainable development in the construction. The composite consists of mixing two materials or more with different mechanical and physical properties in order to development a new hybrid material that has properties not available in the original materials.

In nature, there are many examples of composites including cellulose fibers with the wood material. In the industry, the reinforcement with fibers was the most commonly used [8] [9] [10] [11].

\section{Methodology}

1) Materials: Three kinds of materials were used in this article:

a) Unsaturated polyester resin (SIROPOL 8340-PI): The supplier for this resin is Saudi industrial resins limited (SIR), and the physical and chemical properties of this resin shown in Table 1.

b) Date seeds: were obtained from Karbala canning factory which is raised as waste when the manufacturing of molasses (pekmez). Date seeds were cleaned by complete immersion in distilled water and exposed to ultrasonic waves to remove dust and dirt. After drying by sunlight for a whole day, date seeds were grinding by using micro mill to $(0.5 \mu \mathrm{m})$ particle size, and then the powder was put into the furnace and heated to the temperature $\left(25^{\circ} \mathrm{C}\right)$ for a period of $(5 \mathrm{hr})$ for the disposal of the moisture absorbed completely from the particles.

c) Calcium Carbonate $\left(\mathrm{CaCO}_{3}\right)$ : this material was used as an industrial comparison material, to ensure that the properties of the composite material can be improved when adding particle of date seeds. The supplier for this material is Central minerals \& transport joint stock company with $(0.5 \mu \mathrm{m})$ particle size. Properties of $\mathrm{CaCO}_{3}$ are shown in Table 2.

2) Sample Preparation and tensile test: The samples were fabricating and testing according to ASTM D 638-14 standard [14]. The tensile test was done by tensile testing machine type (WDW-5E) with maximum testing load $5 \mathrm{KN}$. Table 2 is shown the percentages of materials involved in the samples (Table 3 ). 
Table 1. Physical and chemical properties of polyester [12].

\begin{tabular}{cc}
\hline $\begin{array}{c}\text { Physical State } \\
\text { Color } \\
\text { Odor }\end{array}$ & Clear liquid \\
Yellow & Pungent \\
Boiling Point & Not Available \\
Melting Point & Not Available \\
Density & $1-1.3 \mathrm{~g} / \mathrm{cm}^{3}\left[25^{\circ} \mathrm{C}\left(77^{\circ} \mathrm{F}\right)\right]$ \\
Flash Point & $3.6[$ Air $=1]$ \\
Vapor Density & $>1($ Butyl Acetate. $=1)$ \\
Evaporation Rate & Closed cup: $30^{\circ} \mathrm{C}-33^{\circ} \mathrm{C}\left(86-91.4^{\circ} \mathrm{F}\right)[$ Setaflash. $]$ \\
Explosion Limits & Greatest known range: lower: $1.1 \%$, upper: $8 \%($ Styrene $)$ \\
Vapor Pressure & $0.6 \mathrm{Kpa}(4.5 \mathrm{~mm} \mathrm{Hg})$ \\
Solubility & Insoluble in the following materials: cold water \\
Viscosity & Dynamic: $400-600 \mathrm{Mpa} \cdot \mathrm{S}(400-600 \mathrm{Cp})$ \\
& Kinematic: $3.75-5.75 \mathrm{~cm} / \mathrm{S}(375-575 \mathrm{Cst})$
\end{tabular}

Table 2. Properties of calcium carbonate $\left(\mathrm{CaCO}_{3}\right)[13]$.

\begin{tabular}{cc} 
Purity & 98 \\
Physical state and appearance & Powder \\
Color & White \\
Odor & Odorless \\
Boiling point & Not applicable \\
Melting point & $825^{\circ} \mathrm{C}$ \\
PH value & $8-9$ \\
Auto ignition temperature & Not applicable \\
Vapor density & Not available \\
Specific gravity & 2.71 \\
Solubility in water & $1-2$ mg $/ 100 \mathrm{ml}$ \\
Vapor pressure & Not available \\
\hline
\end{tabular}

Table 3. The percentages of materials involved in the samples (wt\%).

\begin{tabular}{cccc}
\hline Sample no. & Polyester & Date seeds & $\mathrm{CaCO}_{3}$ \\
\hline 1 & 99 & 1 & 1 \\
2 & 98 & 2 & 2 \\
3 & 97 & 3 & 3 \\
\hline
\end{tabular}

\section{Results and Discussions}

Figure 1 represents the tensile strength of polyester resin without additives. From this figure, we observe that the maximum stress for the sample before fracture (Tensile strength) can be (25 Mpa) and maximum load (max. load) can 


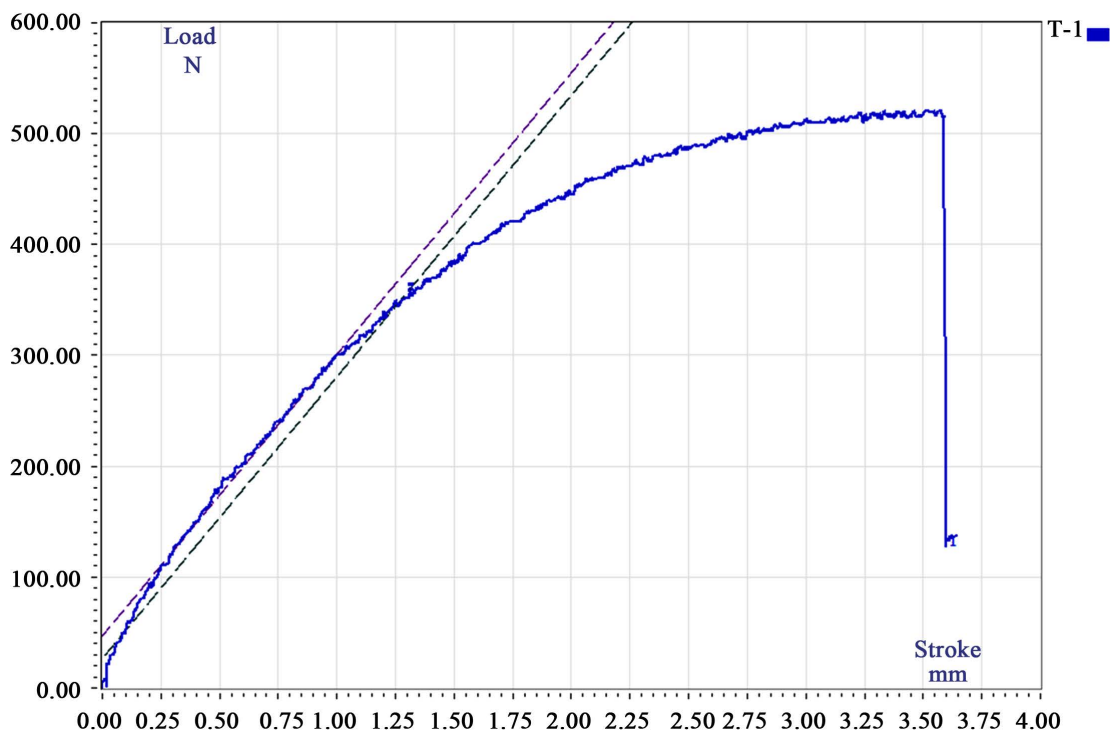

Figure 1. Tensile strength of the polyester resin.

afford before fracture $(520 \mathrm{~N})$. Pure polyester resin without any additives considered as a brittle material which will have low tensile strength as shown in this figure.

Figure 2 shows the tensile strength of the polyester reinforced by ( $1 \mathrm{wt} \%)$ date seeds where it appears that the maximum tensile strength $(30 \mathrm{Mpa})$ and maximum load (max. load) can afford before fracture $(630 \mathrm{~N})$.

Figure 3 shows the tensile strength of the model that contains (1wt\%) from minutes of calcium carbonate, which shows that the maximum stress endures form before fracture (Tensile strength) is (28 Mpa) maximum load (max. load) can afford before fracture $(605 \mathrm{~N})$.

From Figure 2 and Figure 3, we can note that the sample containing (1 wt\% ) particles of date seeds have resistance against fracture is greater than the sample that contains (1 wt\% ) particles of calcium carbonate, it means that natural particles (date seeds) give strengthen reinforcing more with the matrix base (polyester) compared to particles of calcium carbonate, also bonds between particles of date seeds and matrix more powerful because when analyzing these particles we found it contain chemical groups effective bilateral, triangular and ring like $\left(-\mathrm{OH}, \mathrm{CH}_{2}, \mathrm{CH}_{3}, \mathrm{Si}-\mathrm{O}-\mathrm{Si}, \mathrm{C}=\mathrm{C}\right.$, and $\left.\mathrm{Si}=\mathrm{H}\right)$ increases the power of linking between particles and matrix, and that the number of active groups in date seeds particles double totals compare with particles of calcium carbonate and therefore it increases the power of linking between data seeds and the matrix. Also through the figures above note that the amount of the maximum load has been bringing before the fraction be higher in the sample containing ( 1 wt\% ) date seeds particles compared with the sample (1 wt\%) with particles of calcium carbonate.

Figure 4 shows the tensile strength of the polyester reinforced by ( $2 \mathrm{wt} \%)$ date seeds where it appears that the maximum tensile strength (36 Mpa) and maximum load (max. load) can afford before fracture $(746 \mathrm{~N})$. 


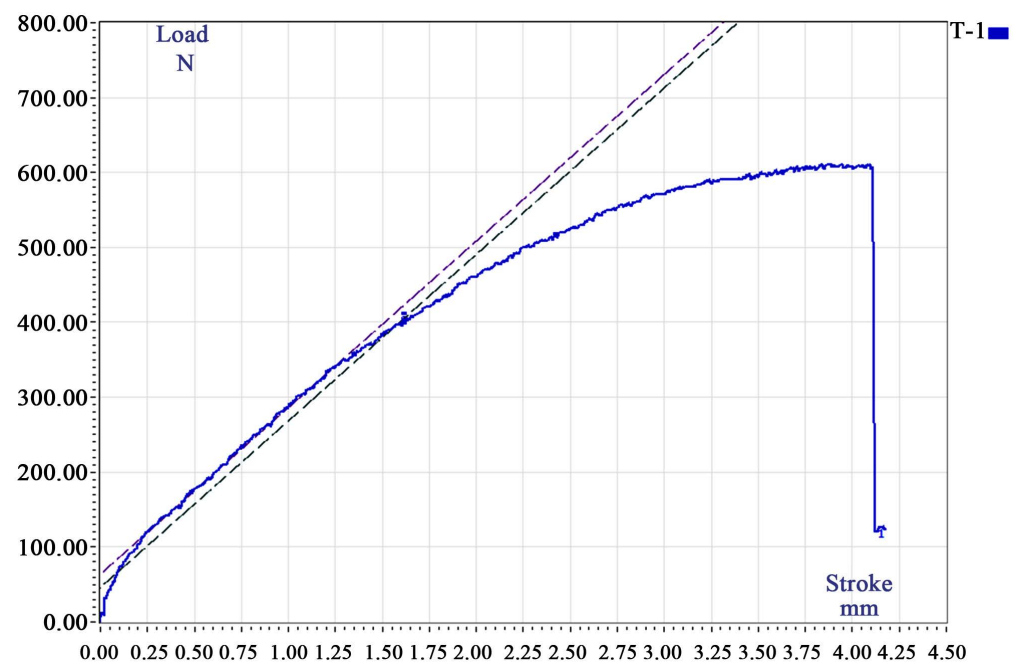

Figure 2. Tensile strength of polyester reinforced by $1 \mathrm{wt} \%$ particles of date seeds.

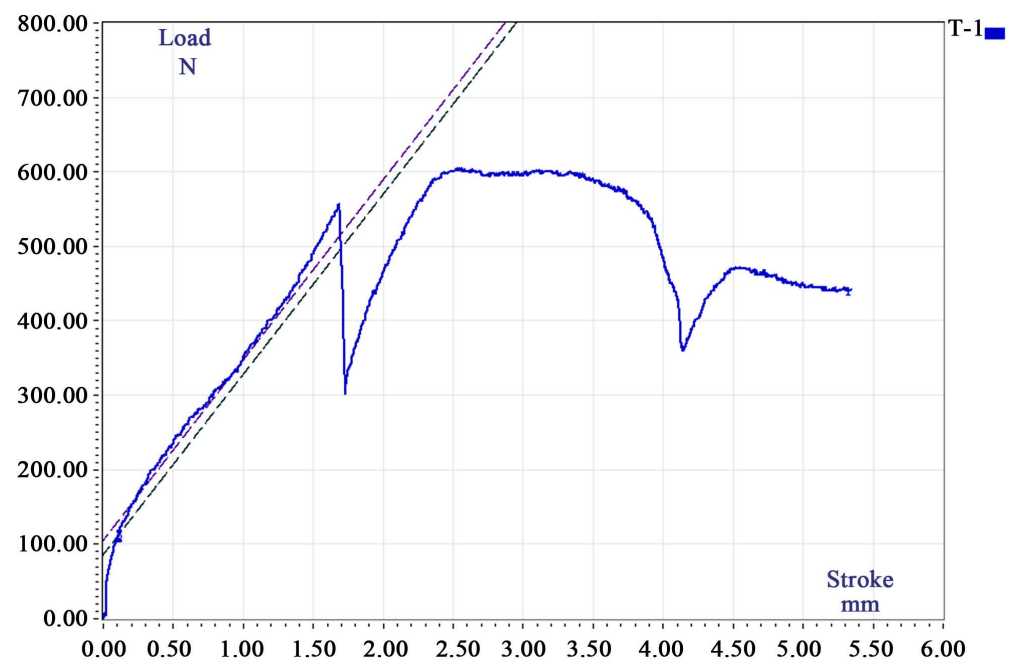

Figure 3. Tensile strength of polyester reinforced by $1 \mathrm{wt} \% \mathrm{CaCO}_{3}$.

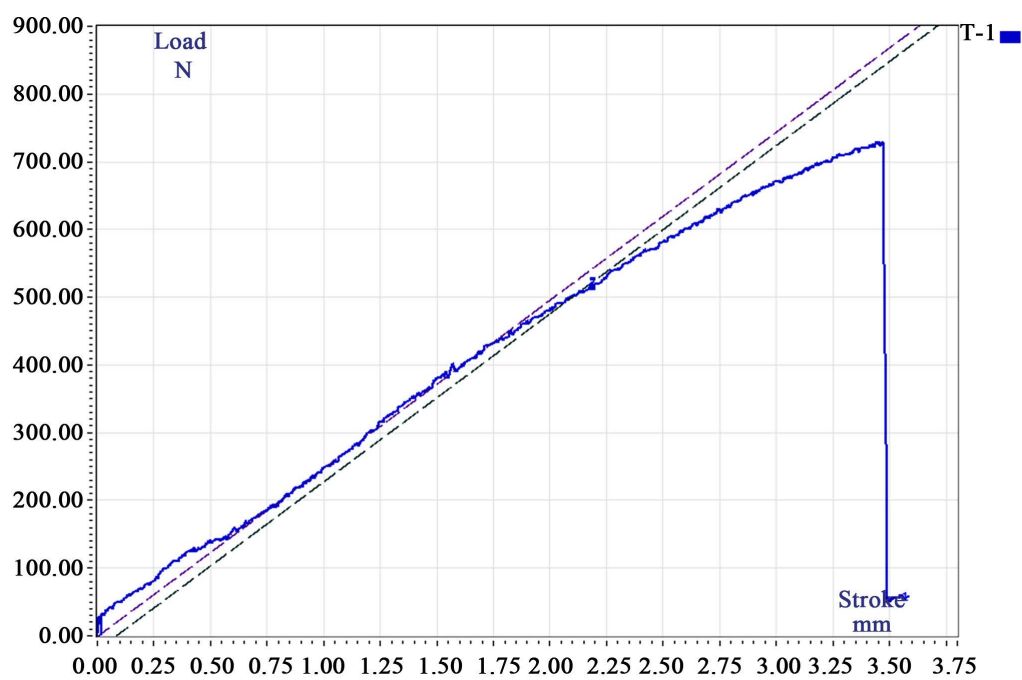

Figure 4. Tensile strength of polyester reinforced by $2 \mathrm{wt} \%$ particles of date seeds. 
Figure 5 shows the tensile strength of the sample (2 wt\% ) with particles of calcium carbonate, which shows that the maximum stress before fracture (Tensile strength) is (34 Mpa) and maximum load (max. load) can afford before fracture $(729 \mathrm{~N})$. Fromthese two figures we see that, the sample containing (2 $\mathrm{wt} \%$ ) particles from date seeds have resistance against fracture is greater than sample containing ( $2 \mathrm{wt} \%$ ) particles from calcium carbonate.

Figure 6 shows the tensile strength of sample containing ( $3 \mathrm{wt} \%$ ) particles of date seeds, so that maximum stress before fracture (Tensile strength) is (50 Mpa) and maximum load (max. load) can afford before fracture (1050 N).

Figure 7 shows a sample that containing (3 wt\% ) with particles of calcium carbonate, which shows that the maximum stress before fracture (Tensile strength) is (47 Mpa) and maximum load (max. load) can afford before fracture (996 N).

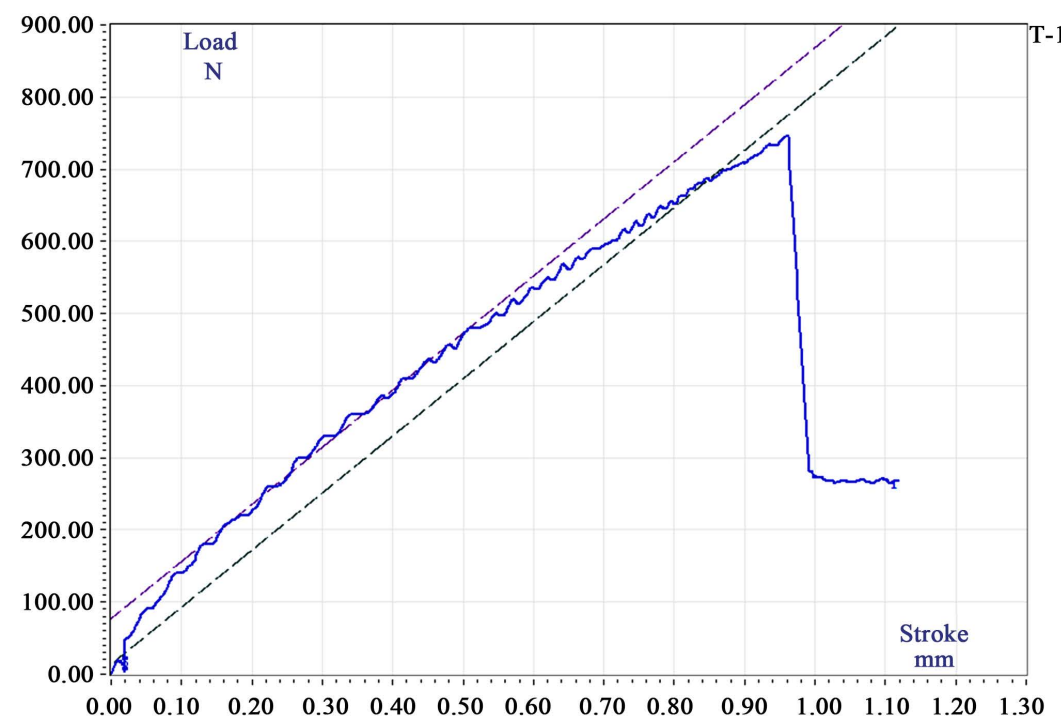

Figure 5. Tensile strength of polyester reinforced by $2 \mathrm{wt} \% \mathrm{CaCO}_{3}$.

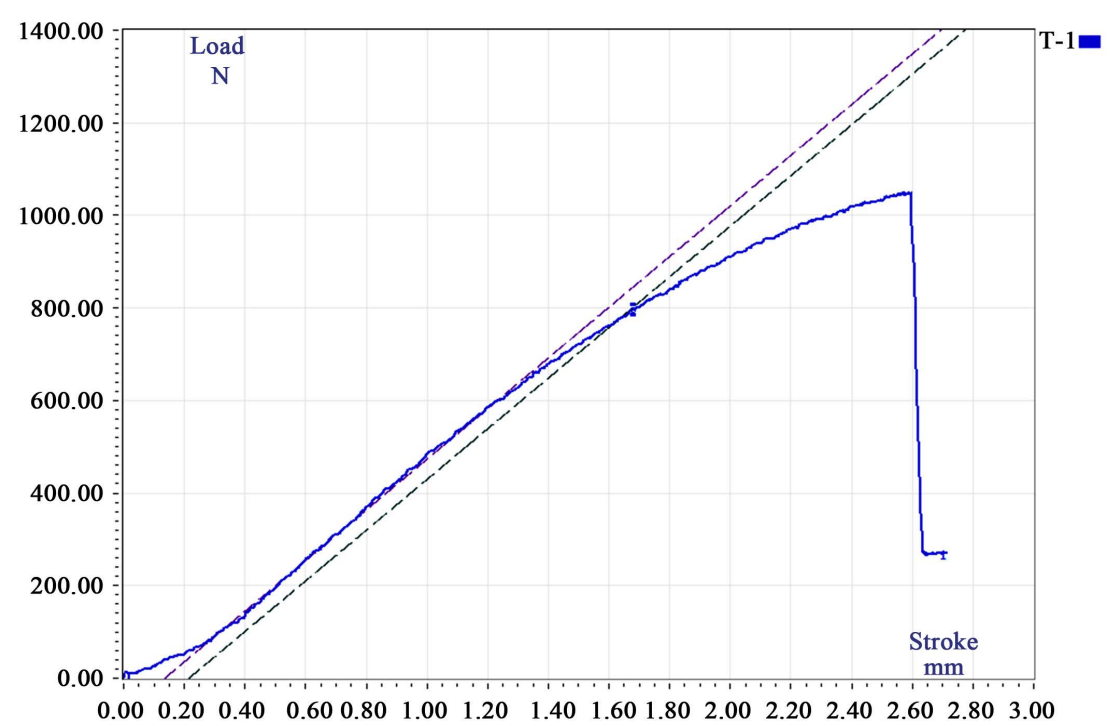

Figure 6. Tensile strength of polyester reinforced by $3 \mathrm{wt} \%$ particles of date seeds. 


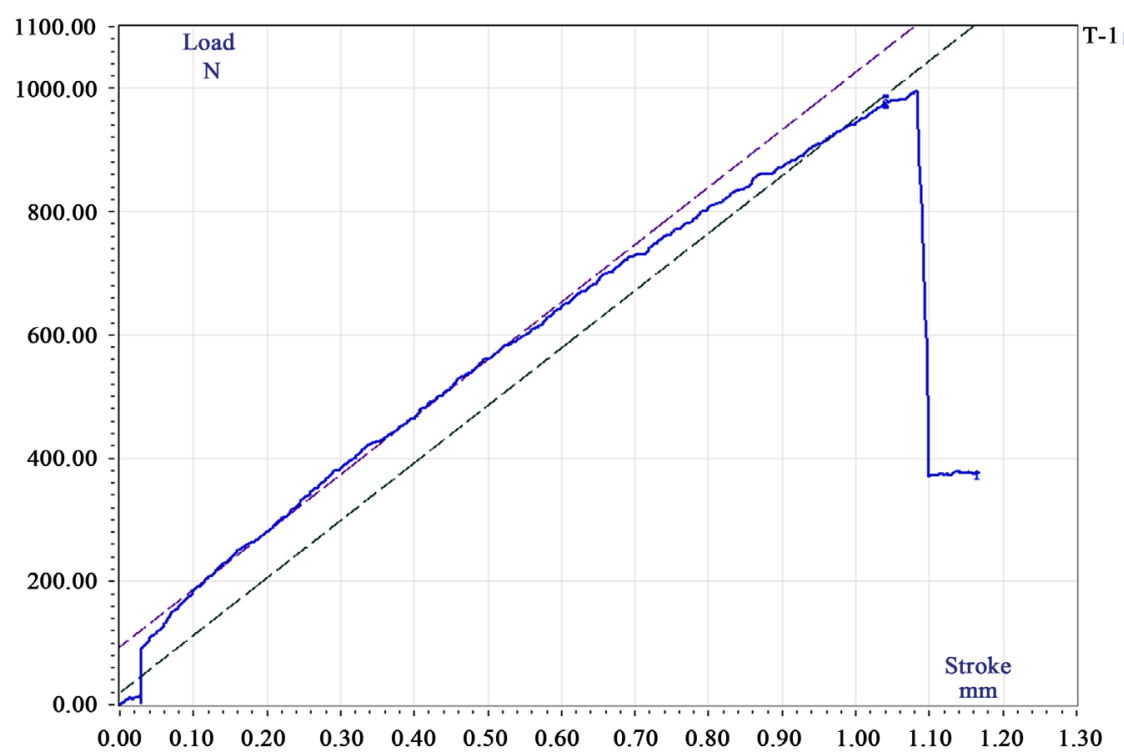

Figure 7. Tensile strength of polyester reinforced by $3 \mathrm{wt} \% \mathrm{CaCO}_{3}$.

From Figure 6 and Figure 7, we can observe that the sample containing (3 $\mathrm{wt} \%$ ) particles of date seeds have resistance against fracture is greater than the sample with (3wt\% ) particles of calcium carbonate. We can note from all the above figures that the samples containing particles of date seeds have high resistance against breakage than samples that contain particles of calcium carbonate because the natural particles give more reinforcement for matrix material plus the strength of links between it and the matrix, we note the ratio of particles of date seeds if it increases more that means the resistance to fracture strength increases.

\section{Conclusion}

Improving tensile strength for samples containing particles of date seeds compared to that containing calcium carbonate, and the strength will increase as a percentage of particles of date seeds increases. Economically, it is possible to use particles of date seeds instead of synthesis compounds in many applications, due to the low cost of manufacturing and good mechanical properties. Treatment of negative effects of these wastes is by integrating them into applications that serve environmental sustainability.

\section{References}

[1] Shukair, A.A., Sharmiti, O., Hatem, M.H., Al-Shibli, M.M. and Mulawah, N.A. (2006) Study of Agricultural Waste Recycling for Industrial and Domestic Uses in Arabic Countries. Arab Organization for Agricultural Development, Khartoum, Sudan.

[2] Al-Mosawi, A.I. (2013) Environmental Impact Study for the Establishment of an Investment Project to Process the Palms Agricultural Waste. Proceedings of $5^{\text {th }}$ International Conference of Environmental Science, 3-5 December 2013, Environmental Research Center, Babylon University, Iraq. 
[3] Al-Mosawi, A.I., Abdulsada, S.A. and Rijab, M.A. (2016) Patent: The Optimum Use of the Sunflower Husks Waste for Manufacturing of Environmentally Friendly Composite Material Contributes to the Sustainability of Natural Resources, Central Organization for Standardization and Quality Control, Iraq.

[4] Ghoneim, O.M. and Abu Zant, M.A. (2014) Sustainable Development, Its Philosophy and Methods of Planning and Measurement Tools. $2^{\text {nd }}$ Edition, Dar Al-Safa for Publishing, Distribution \& Printing, Amman, Jordan.

[5] Al-Mosawi, A.I. (2012) Mechanical Properties of Plants: Synthetic Hybrid Fibers Composites. Research Journal of Engineering Sciences, 1, 22-25.

[6] Abdulsada, S.A., Al-Mosawi, A.I. and Hashim, A.A. (2017) Patent: Using of Date Seeds Waste for Manufacturing of Composite Material Enter in Sustainable Engineering Applications in Order to Reduce Environmental Pollution and Achieve Sustainable Development, Central Organization for Standardization and Quality Control (COSQC), Iraq, No.4848.

[7] Abdulsada, S.A. and Al-Mosawi, A.I. (2015) Tensile Strength of a New Recyclable and Environment Friendly Composite Material. Ciência e Técnica Vitivinícola, 30, 32-40.

[8] Al-Bakr, A.J. (2013) Palm Dates, Its Past and Present, and the New in Cultivation, Manufacture and Trade. 4th Edition, Arab Encyclopedia House, Beirut, Lebanon.

[9] Al-Mosawi, A.I. and Hatif, A.H. (2012) Reinforcing by Palms-Kevlar Hybrid Fibers and Effected on Mechanical Properties of Polymeric Composite Material. Journal of Babylon University, 20, 188-193.

[10] Al-Mosawi, A.I., Abdulsada, S.A. and Rijab, M.A. (2017) Synthesis Effect of Natural/Chemical Blend Nanoparticles on Impact Strength of Sustainable Composite Material. Journal of Catalyst and Catalysis, 4, 1-5.

[11] Al-Mosawi, A.I. (2012) Effect of Reinforcing by Natural and Synthesis Fibers on Thermal Conducting for Composite Material. Journal of Babylon University, 20, 937-942.

[12] (2009) Technical Report, Safety Data Sheet Siropol 8340, Saudi Industrial Resins Limited, Jeddah, Saudi Arabia. sir.msds siropol8340.v03a.doc

[13] (2012) Technical Report, Material Safety Data Sheet: Calcium Carbonate Powder, Central Minerals \& Transport joint Stock Company, Hai Phong city, Vietnam.

[14] (2014) ASTM D638-14, Standard Test Method for Tensile Properties of Plastics, ASTM International, West Conshohocken, PA. 